\title{
Ensino a Distância UlbraOrbe da Universidade Luterana do Brasil: A relação do uso de novas tecnologias e o custo benefício para a Universidade.
}

\author{
Janaína Luisa da Silva Moroni*
}

\begin{abstract}
Resumo: O UlbraOrbe é uma diretoria criada na Universidade com a finalidade de planejar, implementar e coordenar o ensino à distância bem como incorporar novas tecnologias ao ensino em geral.A educação a distância abre um horizonte de opções para a implantação de cursos onde é utilizada a multimídia e hipertexto e, ainda, com vantagens de utilização de ferramentas como o correio eletrônico, fóruns de discussão, e outras mídias, que favorecem a construção de comunidades virtuais de aprendizado. Sua estrutura é formada por uma diretoria, uma área pedagógica e por dois núcleos de produção: o NUTE (Núcleo de Tecnologia na Educação) e o CPA (Centro de Produção Audiovisual), além do grupo de professores tutores.O objetivo da ampliação do ensino a distância, foram os benefícios que as novas tecnologias trouxeram para a ULBRA, tais como a redução de custos de uso de salas de aula, professores, da satisfação do aluno que pode estudar de forma programada por ele mesmo.
\end{abstract}

Palavras chaves: benefícios, fóruns de discussão, correio eletrônico, satisfação do aluno, redução de custos.

\begin{abstract}
The UlbraOrbe is a direction created in the University with the purpose to plan, to implement and to co-ordinate long-distance education as well as incorporating new technologies to education in geral.A education in the distance opens a horizon of options for the implantation of courses where it is used the multimedia and hipertexto e, still, with advantages of use of tools as the e-mail, formuns of quarrel, and other medias, that favor the construction of virtual communities of learning. Its structure is formed by a direction, a pedagogical area and for two nuclei of production: IT NODS it (Nucleus of Technology in the Education) and the CPA (Center of Audiovisual Production), beyond the objective group of professors tutores.O of the magnifying of education in the distance, had been the benefits that the new technologies had brought for the ULBRA, such as the reduction of costs of use of classrooms, professors, of the satisfaction of the pupil who can study of form programmed for he himself.
\end{abstract}

Keywords: benefits, fóruns of quarrel, e-mail, satisfaction of the pupil, reduction of costs.

\footnotetext{
* Graduada em Desenho Industrial (Design) pela Universidade Luterana do Brasil (ULBRA), Integrante da equipe UlbraOrbe como Webdesigner, Instrutora de cursos de informática do SENAC, e-mail: jandesign@pop.com.br
} 


\title{
1. Estrutura do UlbraOrbe - Universidade Virtual
}

UlbraOrbe foi criado no ano de 2003/01, pelo pedido do Reitor da Universidade Luterana do Brasil ao Doutor Ronaldo Bastos, diretor do UlbraOrbe. O grupo era integrado por 9 pessoas de áreas diferentes para o setor pedagógico.

O Ensino a Distância da ULBRA abrange os 8 Campi da Universidade Luterana do Brasil, tais como:

\author{
Campi Cachoeira do Sul / RS \\ Campi Guaíba / RS \\ Campi Gravataí / RS \\ Campi São Jerônimo / RS \\ Campi Torres / RS \\ Campi Canoas / RS \\ Campi Santa Maria / RS \\ Campi Carazinho / RS
}

e 6 ILES pertencentes a Universidade Luterana do Brasil, tais como:

Centro Universitário de Ensino Luterano de Ji-Paraná;

Instituto Luterano de Ensino Superior de Santarém;

Centro Universitário de Ensino Luterano de Manaus;

Centro Universitário de Ensino Luterano de Palmas;

Instituto Luterano de Ensino Superior de Porto Velho;

Instituto Luterano de Ensino Superior de Itumbiara.

A ULBRA pretende desenvolver a EAD em todos os seus Campi e ILES que constituirão a capilaridade do sistema para tanto estabeleceu um cronograma de implantação de Núcleos. Os primeiros que já foram implantados estão localizados em Manaus / MA e Carazinho / RS.

A escolha dessas localidades foi baseada em:

- Interesse da Unidade em criar um Núcleo de Apoio para EAD;

- Demanda apresentada pelas referidas Unidades;

- Estratégia política da Universidade em democratizar o acesso e permanência de alunos no ensino superior.

A central de onde coordena o Ensino a Distância é a unidade localizada na cidade de Canoas. A plataforma utilizada para o EAD é uma parceria com a empresa Web Aula. A ULBRA possui um prédio destinado às salas de computadores, todos os alunos possuem um computador para si, em média a ULBRA oferece 455 computadores e 20 impressoras disponíveis aos alunos. Em cada andar de esse prédio possui dois monitores para auxiliar os alunos.

Os tutores, professores do EAD, possuem uma sala que contém mesas organizadas em ilhas, ao todo são oito computadores para cada professor e uma impressora. Cada mesa possui dois armários. 


\section{2. Área Pedagógica}

A Área Pedagógica tem como finalidade estimular e atuar concretamente na capacitação de recursos humanos, em todos os níveis, visando ao preparo de profissionais docentes que atuarão na educação à distância; bem como aprovar e encaminhar os projetos apresentados a UlbraOrbe e supervisionar as atividades dos setores ligados a UlbraOrbe.

\section{NUTE}

O NUTE é uma oficina de produção de material informatizado para o EAD. È formados por setor de Multimídia, um de WEB e ainda um laboratório de produção e tratamento de imagens além de sala de trabalho especial para professores que mantém projetos em desenvolvimento com a metodologia de EAD.

Ao NUTE compete produzir ou especificar, quando for o caso, o material didático-pedagógico multimídia e hipermídia a ser utilizado nos projetos aprovados pelo CEAD.

Hierarquicamente subordinado à Direção da UlbraOrbe e ao CEAD, gerencia as atividades concernentes à Educação à distância no âmbito dos setores técnicos e tecnológicos da UlbraOrbe.

O CPA (Centro de Produção Audiovisual) além de cuidar da produção de TV em geral (vídeos, programas ao vivo e ou gravados) também administra a TV interativa que, objetiva enviar programação de EAD a todas as unidades de ensino da ULBRA no Rio Grande do Sul e no restante do país. O sistema de TV interativa também poderá se inserir como ferramenta importante nos projetos de universidades corporativa, convênios com prefeituras e secretarias de governo em geral pois sua estrutura técnica permite a instalação de salas de recepção em qualquer lugar e a qualquer distância do estúdio gerador.

O CPA é um conjunto de laboratórios e estúdios de áudio, fotografia e vídeo que atende à comunidade da universidade. Integra, de um lado, o UlbraOrbe prestando apoio operacional e de outro, a Diretoria de Laboratórios e tecnologias Educacionais oferecendo sua infra-estrutura didático-pedagógica.

\section{Atendimento ao Aluno}

Dentro da equipe o UlbraOrbe possui um atendimento especializado em atender os esclarecimentos sobre o Ensino a Distância, sobre suporte técnico, e qualquer duvida e informação que seja solicitada. Este atendimento ocorre nos seguintes turnos: manhã, tarde, e noite para o atendimento ao telefone, e por e-mail. 


\section{Processo Pedagógico}

O processo Pedagógico caracteriza-se por:

- Separação física Professor(a) - Tutor(a)-aluno(a);

- Comunicação bidirecional mediatizada;

- Uso de tecnologias adequadas ao processo de desenvolvimento das atividades didático-pedagógicas.

No Ensino a Distância, o processo ocorre, predominantemente, através do tratamento dado aos conteúdos e formas de expressão mediatizados pelos materiais didáticos, meios tecnológicos, tutoria e avaliação.

As relações estabelecidas pela mediatização pedagógica criam e recriam o sentido da prática educativa, na qual o professor e o aluno utilizam o material instrucional para construir o conhecimento.

\section{Preparação de Tutores, Professores no EAD e suas funções.}

A tutoria é desenvolvida em plantões por professores da disciplina, previamente comunicados aos alunos, utilizando inicialmente vias de comunicação, como o fax, telefone, correio, e-mail e Internet.

No inicio todos os tutores passaram por cursos de aprimoramento no ensino, utilizando as novas ferramentas para este conceito novo de ensinar, Ensino a Distância.

Todos os Tutores planejam seus horários e são comunicados ao setor pedagógicos para a utilização das salas de tutoria, e a cada semestre ocorre curso de atualização.

O desempenho dos tutores é avaliado diariamente, e todo conteúdo que eles desenvolvem é avaliado pelo setor pedagógico.

\section{Controle e avaliação dos alunos}

Os alunos são orientados, atendidos a suas consultas, dirigidos e acompanhados o desenvolvimento de seus estudos pelo Tutor.

Pelo sistema da plataforma da WebAula do UlbraOrbe, os tutores e equipe técnica possuem acesso a quantas horas e a que conteúdo o aluno esteve, porém este tipo de informação não influencia diretamente na avaliação de nota.

A avaliação do aluno é dada pelo rendimento dos trabalhos, exercícios, e provas que o Tutor realiza para os alunos.

\section{O Auto-estudo x Avaliação.}

Ao acessar a disciplina pela plataforma do UlbraOrbe, o aluno encontrará um esquema, resumo da disciplina a ser estudada. Para auxiliar este processo de autoestudo, o Tutor realiza indicações de como ter um bom aproveitamento do estudo.

O conteúdo da disciplina é organizado de modo ao estudante ter noção de onde está navegando e controle de seu estudo. 
Toda disciplina possui exercícios de auto-avaliação seguidos das correspondentes soluções.

Se o aluno precisar ele poderá consultar o Glossário, a Biblioteca e o Apêndice documental.

$\mathrm{Na}$ avaliação final o aluno comparece a unidade da ULBRA para entregar ou realizar a prova junto ao seu tutor, que já desde o inicio do EAD o tutor combina com os alunos a um encontro presencial para se conhecerem e conhecer toda a estrutura da ULBRA e os serviços que o aluno pode usufruir.

\section{Tecnologia aplicada do UlbraOrbe}

A Plataforma LMS (Learning Management System) - Sistema de Gestão de Aprendizagem - utilizada pela UlbraOrbe para o gerenciamento do ambiente virtual é a WebAula. Oferece várias ferramentas de interação síncronas (on-line, tempo real) e assíncronas (off-line, cada um acessa e participa a seu tempo), bem como controles e relatórios que permitirão ao professor e seus alunos uma integração adequada às perspectivas que os processos de ensino e de aprendizagem requerem para o sucesso desta iniciativa.

Para a utilização de toda a comunidade virtual UlbraOrbe (não importando, aqui, a disciplina ou curso em que você está matriculado).

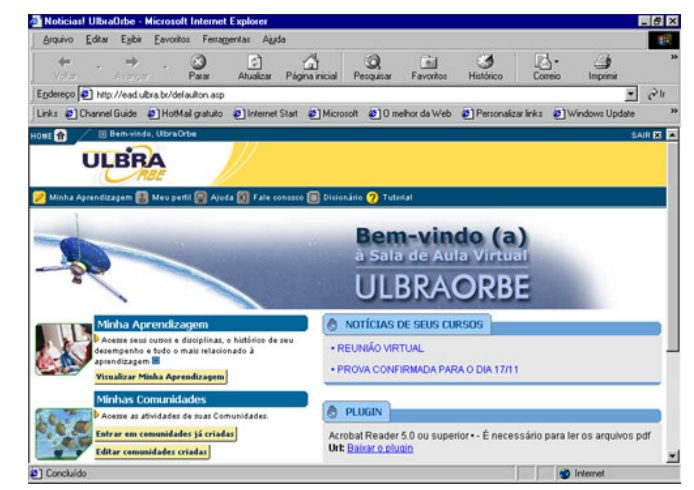

figura 1- tela de apresentação da disciplina ou curso matriculado.

As ferramentas disponíveis nesta página são:

Minha Aprendizagem: permite o acesso à(s) disciplinas(s) em que você está matriculado.

Meu Perfil: permite atualizar dados do aluno, como e-mail e telefone.

Ajuda: permite visualizar uma tela de Perguntas e Respostas que a Equipe UlbraOrbe julgar necessárias para sanar dúvidas que são comuns à maioria dos alunos EAD.

Fale Conosco: permite comunicar-se via e-amil com a equipe UlbraOrbe.

Dicionário: permite acessar um dicionário de termos gerais sobre informática (o dicionário individualizado da disciplina estará disponível no ambiente próprio da disciplina, sob o título de Glossário). 
Tutorial: roda um pequeno programa que explica o funcionamento das ferramentas disponíveis.

Noticias de seus Cursos: Nesta tela inicial, estarão os links relativos às notícias postadas pelo professor ou pelas equipes técnica e pedagógica.

Uma vez dentro da primeira página - Home, pode-se clicar sobre Minhas Aprendizagens, aparecendo, então, outra página que mostra a(s) disciplina(s) em que o aluno está matriculado. Clicando no nome da disciplina, entra-se no ambiente virtual próprio da sua disciplina.

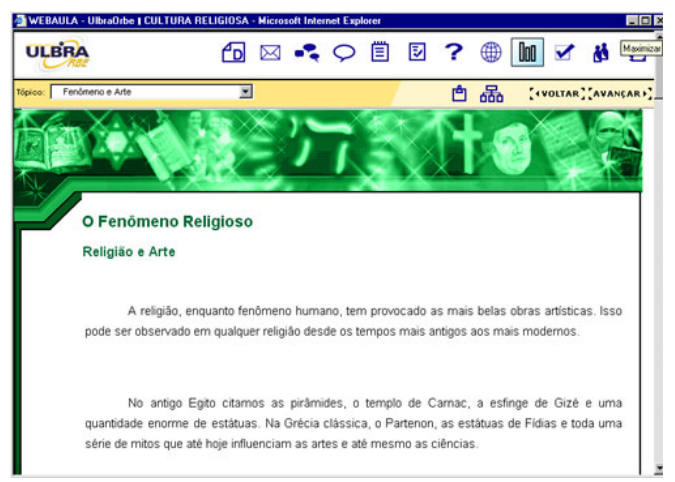

Figura 2 - exemplo de identidade visual de uma das disciplinas (cultura religiosa)

Neste ambiente, o aluno tem sua disposição uma série de outras ferramentas que são:

CALENDÁRIO: ferramenta informativa alimentada pelo professor com datas e dados pertinentes a avaliações e trabalhos.

MENSAGEM: ferramenta assíncrona, onde aluno pode mandar mensagens pessoais para qualquer colega de usa turma virtual. Se o aluno quiser mandar uma mensagem a todos os colegas, basta selecionar o primeiro nome e arrastar o mouse até encontrar o último nome da lista, digitar sua mensagem e remetê-la. Assim que o(s) destinatário(s) entrar(em) no ambiente da disciplina, receberá(ao) sua mensagem.

FÓRUM: ferramenta assíncrona que serve como um mural onde você tem a opção de postar e, quem quiser, professor ou colega(s), pode ler e/ou responder à sua colocação. Nesta ferramenta, o conjunto de mensagens postadas e respondidas, fica sempre disponível para o acompanhamento das discussões.

CHAT: oferece três possibilidades de uso, que são:

- Pedido de Atendimento Individual: permite mandar uma mensagem para a equipe UlbraOrbe. Geralmente usada para pedir apoio técnico.

- Pedido de Atendimento do Professor: permite mandar uma mensagem para o professor responsável pela disciplina. Geralmente usada para um atendimento individual. 
- Pedido de Chat: ferramenta síncrona que lhe permite entrar em um bate-papo on-line com seu professor e colegas. Pode ser usado somente por alunos para conversação entre si e pode ser usado pelo professor para conversações agendadas com antecedência.

ANOTAÇÕES: oferece um caderno de notas virtual onde o aluno pode fazer anotações sobre a matéria (ou o que o aluno desejar). Estas anotações serão guardadas em um banco de dados e ficarão sempre disponíveis para leitura e / ou complementação. Permite a impressão, a qualquer momento, de suas anotações.

AVALIAÇÃO: possibilita o acesso à(s) prova(s) de final de curso. Esta ferramenta só fica disponibilizada se seu professor quiser realizar uma prova virtual.

FAQ (Frequently Asked Questions): perguntas mais freqüentes. Ferramenta alimentada pelo professor com as perguntas mais freqüentes dos alunos e respectivas respostas. Possibilita que o aluno, se tiver alguma dúvida, olhe antes esta ferramenta para ver se já não está respondido.

GLOSSÁRIO: é o dicionário particular da disciplina que trata de termos relacionados à matéria desenvolvida no ambiente virtual da disciplina. Ferramenta alimentada pelo professor.

BIBLIOTECA VIRTUAL: permite que o professor coloque à disposição de seus alunos arquivos de vários formatos para Download, dicas que julgar necessárias e URLs de sites pertinentes à matéria trabalhada. Nesta ferramenta também é dada ao aluno a condição de disponibilizar arquivos próprios que queira socializar com o grupo de colegas.

EXERCÍCIOS: ferramenta que permite acessar exercícios específicos de apoio ao estudo. Esta ferramenta fica disponível somente se o professor inserir algum exercício para aquele tópico que está sendo visualizado.

COLEGA ON-LINE: ferramenta que dispõe de quatro tipos de informação: Professor on-line, Professor Off-line, Colegas On-line e Colegas Off-line. Permite enviar uma mensagem individual ao endereço de e-mail do professor ou colega selecionado.

ÁREA DE TRABALHOS: onde o professor colocará toda a sua proposta de trabalhos. O aluno deverá acessar esta ferramenta para receber os trabalhos e, após, remetê-los de volta ao sistema, para a avaliação dos mesmos, pelo professor.

A organização do conteúdo das aulas virtuais ocorre da seguinte forma:

Módulo: corresponde a um capítulo da matéria da disciplina.

Tópicos: são as subdivisões do módulo onde ocorre à explicação detalhada da matéria da disciplina. 
Para humanizar as aulas foi criado o boneco Zé Ciência, um personagem que assuem as características de cada disciplina. Uma disciplina de matemática, ele aparece vestido de professor de matemática, se for uma disciplina do curso de medicina ele aparecerá vestido de médico. Este personagem é o principal do UlbraOrbe, além dele tem-se outros que são os auxiliares nas explicações.

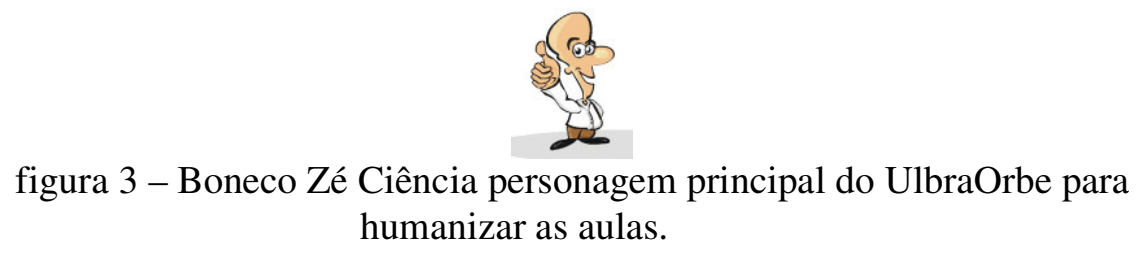

\section{Competência da UlbraOrbe}

- Cumprir e fazer cumprir a legislação aplicável, o Estatuto e o Regimento Interno da ULBRA e outras normas / regulamentos, bem como as decisões administrativas;

- Coordenar a elaboração do plano anual, abrangendo o planejamento, a execução e a avaliação das atividades das suas coordenações;

- Coordenar e assegurar a execução da programação do UlbraOrbe;

- Coordenar a elaboração e produção do material instrucional dos cursos;

- Propor à autoridade competente a constituição de comissões de grupos de trabalhos destinados a realizar tarefas específicas relacionadas à Educação a Distância;

- Propor atividades relacionadas a estudos e pesquisas relacionadas a EAD;

- Desenvolver em parcerias com outros Centros, cursos que utilizem metodologia de ensino a distância.

\section{Estudo comparativo dos alunos inscritos no ano de 2003 do primeiro e segundo semestre, e do primeiro semestre de 2004.}

No ano de 2003 foram inscritos aproximadamente 2.150 alunos apenas no campus de Canoas. Para o primeiro semestre de 2004 foram inscritos até agora 1.970 alunos também no campus Canoas. A tendência é crescer ainda mais o número visto que tem muitos alunos que se matriculam em março.

Mesmo as disciplinas e curso oferecido com desconto em relação ao assistir as aulas no método tradicional, as vantagens econômicas para a ULBRA são bem significativas. 


\section{Conclusão}

Na primeira experiência do EAD do UlbraOrbe já obtiveram bons resultados, e com o passar dos meses aprimorou-se em todos os sentidos o EAD da ULBRA. Com a criação do personagem os alunos sentiram as aulas mais agradáveis, o sucesso foi tanto que até brindes com a figura dele é solicitado pelos estudantes e professores.

A ULBRA ganhou credenciamento do MEC e elogios pelo ótimo desempenho do laboratório de criação, atendimento ao aluno, marketing, didático e pedagógico. Inclusive levaram amostras do trabalho efetuado no UlbraOrbe para mostrar de exemplo de um caso de sucesso.

O segredo esta em administrar com pesquisa, estudos, organização e trabalho em equipe formado por profissionais qualificados, e sempre em busca de novas tecnologias que aprimorem o ensino de estudantes à distância.

\section{Bibliografia}

FREIRE, Paulo. SHOR, Ira. Medo e Ousadia: O cotidiano do professor. Rio de Janeiro. Editora Paz e Terra, 1987

Guaranys, L.R. dos. Castro, C.M. (1979). O ensino por correspondência: uma estratégia de desenvolvimento educacional no Brasil. Brasília: IPEA.

(Nunes, 2003) NUNES, Ivônio Barros. Noções de educação à distância. Disponível na Internet. URL: http://www.edudistan.com/ponencias/Ivonio\%20Barros\%20Nunes.htm. Acessado em agosto de 2003.

(Jaques, 1997) JAQUES, Patrícia Augustin. Técnicas de Disponibilização de Informação através da Internet em vista da Educação a Distância.

UNIVERSIDADE LUTERANA DO BRASIL. Catálogo 2003 ULBRA, 2003. Canoas, 2003. 222p.

UNIVERSIDADE LUTERANA DO BRASIL. Manual do Aluno, 2003. Canoas, 2003. $19 \mathrm{p}$.

UNIVERSIDADE LUTERANA DO BRASIL. Manual do Tutor, 2003. Canoas, 2003. 30p.

UNIVERSIDADE LUTERANA DO BRASIL. Manual do Material Instrucional, 2003. Canoas, 2003. 22p. 